\title{
Prevalence of Bovine Tuberculosis Gross Lesions in Doukkala slaughterhouses, Morocco
}

\section{Aboukhassib Hamid, PhD Student and Veterinary \\ Bitar Abdelali, Professor}

Nutritional Physiopathology and Toxicology Team, Department of Biology, Faculty of Sciences - UCD El Jadida, Morocco

Haraji Mohammed, PhD Veterinary

Laboratory of Biotechnology, Biochemistry and Nutrition,

Faculty of Sciences of El Jadida, Morocco

Yahyaoui Azami Hind, Researcher

Department of Infectious Diseases, University of Georgia, Athens, USA

Bouslikhane Mohammed, Professor

Department of Veterinary Pathology and Public Health,

Hassan II Agronomic and Veterinary Institute, Rabat, Morocco

\begin{abstract}
In Morocco, tuberculosis (TB) is a major zoonotic disease with very serious hygienic and economic impacts. Our study aimed to investigate bovine tuberculosis in two Moroccan slaughterhouses in Doukkala area based on the observation of macroscopic gross lesions. 4198 cattle were examined for tuberculosis lesions during the period of end of May 2014 to July 2015 .The results showed that $64.4 \%$ of cattle with TB lesions were male with a dominant age of less than or equal to 2 years $(67.2 \%)$. Females represented only $35.6 \%$ with a dominant age between 4 and 8 years $(62.3 \%)$. The dominant breed was the cross breed of imported and local breeds with $95.4 \%$. Tuberculosis-like lesions were observed in 194 animals (4.6\%) including 10 $(5.15 \%)$ of generalized and $184(94.85 \%)$ of localized lesions, mainly encountered in the lungs (44.83\%), the head lymph nodes (42.32\%) the liver and its associated lymph nodes $(9.41 \%)$. An estimated overall daily prevalence of $4.6 \%$ and a daily average of $5.4 \%$ (95\% CI: $4.7-6.1 \%$ ) were noted. Compared data obtained from the slaughter database $1.97 \%$ (95\% CI: $1.8-2.4)$, this prevalence is more than twice of estimated average $(\mathrm{RR}=2.34)$. This assumes that routine inspection leaves more than $50 \%$ of animals with suspicious lesions. On the other hand, 390 gross lesions were collected for culturing. An isolation frequency of Mycobacterium of $85.6 \%$ was obtained and the LPJ and Herrold seem to be the best culture media.
\end{abstract}


Keywords: Bovine tuberculosis, post-mortem, gross lesions, prevalence, Culture, Mycobacterium, Slaughterhouses, Morocco

\section{Introduction}

Bovine tuberculosis (BTB) is a chronic infectious disease caused by Mycobacterium bovis (M.bovis). It is widely distributed throughout the world and could be transmitted to human, which constitutes public health concern (Ameni and Erkihun, 2007). The transmission of BTB to human could occur via the consumption of unpasteurized infected milk and infected meat (Cousins et al., 2001). The respiratory route is considered to be the primary mode of infection within cattle (Morris et al., 1994). BTB infection is also transmissible from cattle to humans directly by aerogenous route and through direct contact with material contaminated by nasal and oral secretions from infected animals (WHO, 1994), meanwhile occupational infection may occur among farmers, veterinarian, and slaughterhouse workers (Biet et al., 2005).

The global prevalence of human tuberculosis caused by $M$. bovis has been estimated to be $3.1 \%$ of all tuberculosis cases, accounting for $2.1 \%$ and $9.4 \%$ of pulmonary and extra- pulmonary tuberculosis cases respectively (Cosivi et al., 1998). The prevalence of $M$. bovis among human TB cases is low in the developed world (O'reilly and Daborn, 1995; Whipple et al., 1996) but its importance in most of the developing countries is unknown and could be high due to a lack of control programmes and the high prevalence of BTB (Neill et al., 1994).

Zoonotic TB can also be considered a socio-economic disease; it has a negative impact on livestock production in developing countries through reduced production efficiency, carcass or organ condemnation and restriction of international trade. The detection of infected animals is mainly limited to the routine slaughterhouse inspection.

In Morocco, bovine tuberculosis has been reported in cattle since 1939 as a result of importation of cattle from Europe and the cases have increased with intensification of dairy livestock (Fikri, 1997). Officially, tuberculin skin and ELISA tests and slaughter inspection are the current control strategy applied in Morocco. However, due to budget constraints for breeder compensation, there is no systematic BTB screening of cattle at a national level (ONSSA, 2017).Live animal teting is limited to medium and large cattle dairy herds.

Identification of $M$. bovis by culture and molecular methods is important for a definitive diagnosis (Corner et al., 2012). As the slaughterhouses in Morocco do not have diagnosis facilities for rapid confirmation of detected BTB macroscopic lesions, the visual inspection of 
carcasses and offal remains a usual the only technique for monitoring the prevalence of BTB in Morocco.

It's within this framework that our study is undertaken to achieve the following objectives:

- Assess the prevalence of BTB in slaughterhouses of Doukkala region (Morocco),

- Determine the epidemiological characteristics of the slaughtered cattle with evident BTB-like lesions,

- Use four media culture to isolate Mycobacterium from these lesions.

\section{Materials and methods}

The study was conducted in Doukkala's slaughterhouses (El jadida and Had Ouled Frej cities) from end of May 2014 to July 2015. Doukkala region has enormous potential to be a preferred destination for businessmen wishing to invest in the agro-industrial sector. Thanks to its important road and rail infrastructure, in addition to its proximity to three ports and major urban centers (Casablanca and Marrakech among others), this region has become a real national agro-industrial hub. The agricultural sector in the Doukkala region contributes up to $10 \%$ of the national agricultural Gross Domestic Product (GDP) and to $22 \%$ to regional GDP. The dairy sector is among the most productive sectors in the region with a total of 147,000 dairy cows (95\% improved breeds) and 43,200 dairy farmers. Doukkala holds also large markets where animals from different region of Morocco and different ages and breeds are mixed and brewed, thus facilitating diseases transmission including tuberculosis. Meat inspection is governed by regulations that provide for ante-mortem and post-mortem examinations. It is carried out by assigned meat veterinary inspectors in each abattoir. The procedures employ meat inspection protocols issued from Moroccan health veterinary authorities. They involve visual examination and palpation of organs such as the lungs, the liver and kidneys, in addition to palpation and incision of retropharyngeal, tracheobronchial, mediastinal and other lymph nodes. Further examinations of other lymph nodes and organs, or the whole carcass are performed whenever lesions are detected in one of these tissues. The whole carcass is condemned in generalized BTB, associated with cachexia involving multiple lymph nodes, while the whole organs (or their parts) are discarded if large tuberculous lesions are found in their parenchyma or associated lymph nodes. When gross lesions of BTB are found in any of the tissues, the animal is classified as having lesions (BO, 2001).

In our study, 4,198 cattle slaughtered were examined by visual and physical inspection of external and internal organs under sufficient light, with special focus on systemic portal lymph nodes for possible presence of nodules. 319 samples of gross lesions suggesting BTB were collected from 
194 infected animals in sterile plastic containers and were conveyed to Hassan II Agronomic and Veterinary Institute in Rabat and stored at $-20{ }^{\circ} \mathrm{C}$ for Mycobacterium culture purpose (Table 1).

Table 1: Distribution of the samples among BTB cases as recognized by gross lesions examination

\begin{tabular}{lcc}
\hline Sample nature & Number & $\begin{array}{c}\text { Percentage } \\
(\boldsymbol{\%})\end{array}$ \\
\hline Retro-pharyngeal lymph nodes & 129 & $(66.5)$ \\
Pulmonary lymph nodes & 89 & $(45.9)$ \\
Pulmonary parenchyma & 54 & $(27.8)$ \\
Hepatic parenchyma & 20 & $(10.3)$ \\
Retro-hepatic lymph nodes & 10 & $(5.2)$ \\
Mandibular lymph nodes & 6 & $(3.1)$ \\
Pleural lesion & 4 & $(2.1)$ \\
Mesenteric lymph nodes & 2 & $(1.0)$ \\
Renal lesion & 2 & $(1.0)$ \\
Iliac lymph nodes & 1 & $(0.5)$ \\
Pre-scapular lymph nodes & 1 & $(0.5)$ \\
Pericardial lesion & 1 & $(0.5)$ \\
\hline Total & 319 & \\
\hline
\end{tabular}

The samples were processed and cultured according to the method described in the "Laboratory Methods in Veterinary Mycobacteriology" manual (United State Department of Agriculture, 1985). The samples from each animal having shown suspicious lesions of tuberculosis were treated according to the method described above and pooled with approximately $5 \mathrm{~g}$ of tissues to obtain a ground material that will serve as an inoculum.

For each inoculum, two different culture media were used excepting two samples for witch three media were used. Cultivation involved samples from 194 animals in a total of 390 culture tubes. The media used for the primary culture of Mycobacterium from BTB-like lesions were mainly eggbased media: Lowenstein-Jensen without glycerine (LJ), Lowenstein-Jensen with glycerine (LJG), Lowenstein-Jensen enriched with pyruvate (LJP) and Herrold. Each sample was seeded in two different media, especially in order to increase the chances of having mycobacterial colonies. Transplanting was carried out for any colony having shown the Acido-Alcohol-Resistant (AAR) character on the Proskauer and Beck (P \& B) liquid medium (Proskauer and Beck,1898) and then on one of solid media. The detailed assessment of the cultivations according to the media used and the origin of the samples is presented in Table 2.

The combination of culture media that has been frequently used for each sample is that of LJP and Herrold media. When monitoring incubated cultures, suspicious colonies were systematically stained using the ZiehlNeelsen staining $(\mathrm{ZN})$ to check the AAR character of the bacilli. The results 
are noted to ensure the simple traceability. The sample is considered positive if the culture is confirmed positive in at least one of the used media .

An Excel MS Office database has been developed to ensure both data capture for each sample and crop monitoring data using the function of the "PivotTable Report". The analysis features of the same software were used for data analysis and results presentation.

Table 2: Distribution of the media used for Mycobacterium culture

\begin{tabular}{lcc}
\hline Culture media & Number & $\begin{array}{c}\text { Percentage } \\
(\%)\end{array}$ \\
\hline LJ with sodium pyruvate (LJP) & 144 & $(36.9)$ \\
Herrold (Herr) & 106 & $(27.2)$ \\
Lowenstein Jenson (LJ) & 89 & $(22.8)$ \\
LJ with glycerin (LJG) & 51 & $(13.1)$ \\
\hline Total & 390 & $(100)$ \\
\hline
\end{tabular}

\section{Results}

\section{A-Tuberculosis-like lesions}

Results showed that $64.4 \%$ of cattle with macroscopic gross lesions were male with a dominant age of less than or equal to 2 years $(67.2 \%)$. Females represented only $35.6 \%$ with a dominant age between 4 to 8 years $(62.3 \%)$. The dominant breed was the cross bred animals originated from local or imported breedings with $95.4 \%$ (Table 3).

Table 3: Individual characteristics of tuberculous cattle used for sampling

\begin{tabular}{|c|c|c|c|}
\hline Feature & & Number & $(\%)$ \\
\hline $\begin{array}{l}\text { Originated } \\
\text { production }\end{array}$ & Dairy & 174 & $(89.7)$ \\
\hline system & Beef & 20 & (10.3) \\
\hline \multirow{3}{*}{ Sex } & Female & 69 & (35.6) \\
\hline & Male & 125 & $(64.4)$ \\
\hline & Total & 194 & (100) \\
\hline \multirow{11}{*}{ Age class } & Females & & \\
\hline & $\leq 2$ years & 8 & (11.6) \\
\hline & 2 to 4 years & 7 & (10.1) \\
\hline & 4 to 8 years & 43 & $(62.3)$ \\
\hline & $>8$ years & 11 & (15.9) \\
\hline & Subtotal & 69 & $(100)$ \\
\hline & Males & & \\
\hline & $\leq 2$ years & 84 & $(67.2)$ \\
\hline & 2 to 4 years & 41 & (32.8) \\
\hline & Subtotal & 125 & $(100)$ \\
\hline & Total & 194 & (100) \\
\hline \multirow{3}{*}{ Breed } & Cross breed & 185 & $(95.4)$ \\
\hline & Imported purebred & 9 & $(4.6)$ \\
\hline & Total & 194 & (100) \\
\hline
\end{tabular}


Taking into account the origin of BTB cattle sampled, we noted that they come mainly from Markets close to the town of El Jadida namely Sidi Bennour (36.6\%) and Had Ouled Frej (28.9\%) (Table 4).

Table 4: Reported origin of tuberculosis cattle cases based on gross lesions.

\begin{tabular}{lcc}
\hline Declared origin & \multicolumn{2}{c}{ Cattle number \% } \\
\hline Sidi Bennour & 71 & $(36.6)$ \\
Had Ouled Frej & 56 & $(28.8)$ \\
Sebt Douib & 44 & $(22.7)$ \\
Other areas & 23 & $(11.9)$ \\
\hline Total & $\mathbf{1 9 4}$ & $\mathbf{( 1 0 0 )}$ \\
\hline
\end{tabular}

The majority of the macroscopic lesions observed on tuberculous bovine carcasses were detected at the level of the ribcage (44.83\%) and concerned the lungs and bronchial lymph nodes, as well as at the level of the head, mainly in the retro-pharyngeal lymph nodes (42.32\%) and also the liver and its lymph nodes (Table 5 and Photo 1 ).
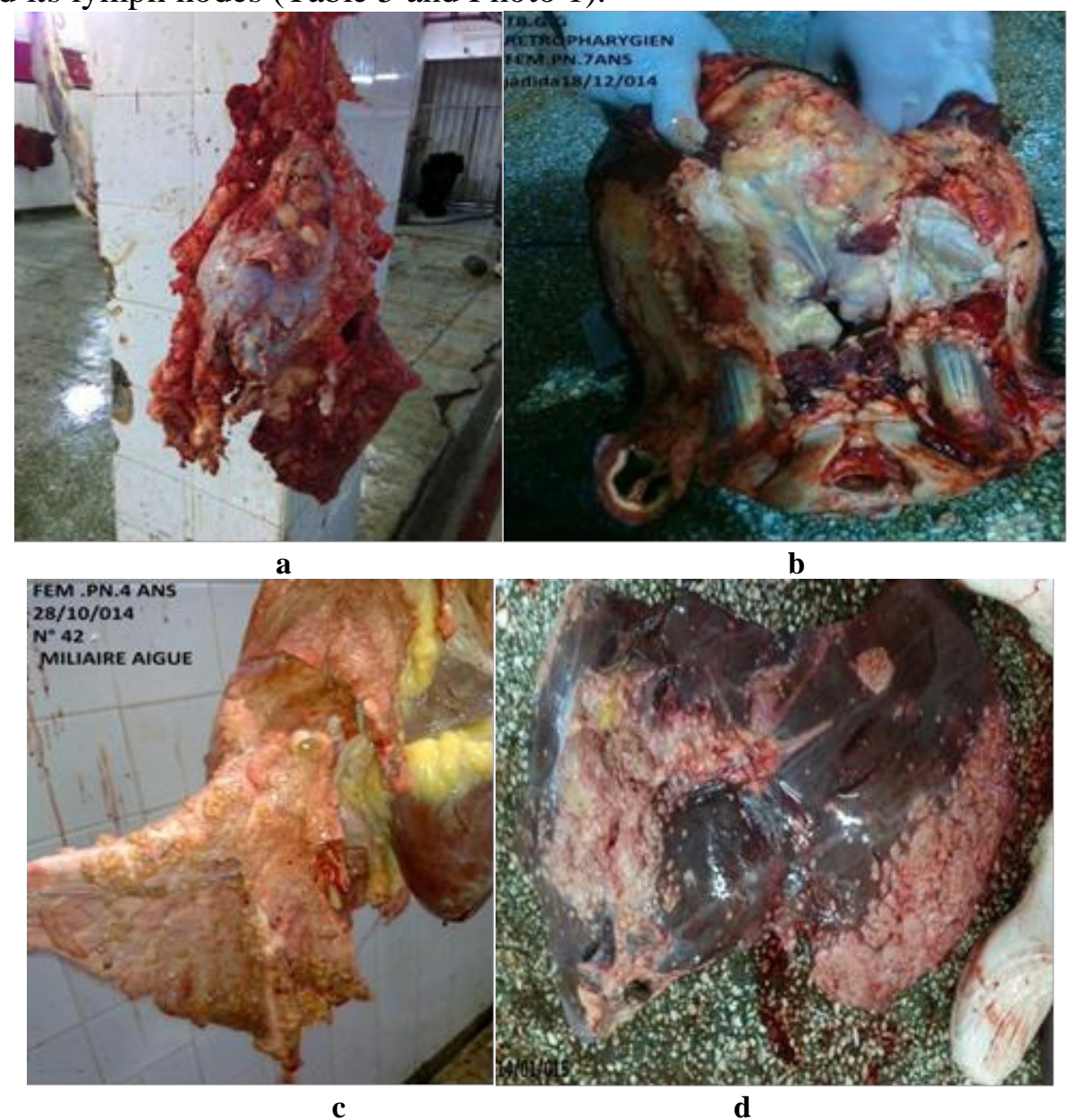

Photo 1: Tuberculous lesions in different organs of cattle in Doukkala area. a-Heart (pericardium), b-Retropharyngeal nodes c-Lungs, d-Liver 
Table 5: Localisation and frequencies of tuberculosis lesions

\begin{tabular}{lcc}
\hline Location of lesions & \multicolumn{2}{c}{ Grosse BTB lesions } \\
& Number & $(\%)$ \\
Lungs* & 143 & $(44.83)$ \\
Head* & 134 & $(42.32)$ \\
Liver* & 30 & $(9.41)$ \\
Pleura & 4 & $(1.25)$ \\
Kidneys & 2 & $(0,63)$ \\
Mesenteric lymph nodes & 2 & $(0.63)$ \\
Pericardium & 1 & $(0.31)$ \\
Prescapular lymph nodes & 1 & $(0.31)$ \\
Iliac lymph nodes & 1 & $(0.31)$ \\
\hline
\end{tabular}

*Organ and lymph nodes

Among observed progressive tuberculosis forms, the stabilized primary complex is reported in $80.4 \%$ of cases followed by stabilized nodular tuberculosis with $10.8 \%$ as mentioned in Table 6.

Table 6: Frequencies related to the progressive stage of bovine tuberculous lesions.

\begin{tabular}{lcc}
\hline Evolutionary stage & Number & $(\%)$ \\
\hline Stabilized primary complex & 156 & $(80.4)$ \\
Chronic organ tuberculosis & 8 & $(4.1)$ \\
Generalized tuberculosis & 7 & $(3.6)$ \\
Stabilized nodular & 21 & $(10.8)$ \\
tuberculosis & 2 & $(1.1)$ \\
Absence of lesions $*$ & 194 & 100 \\
\hline Total & &
\end{tabular}

Out of 4,198 cattle carcasses inspected, 194 (4.6\%) showed tuberculosis-like lesions. Generalized tuberculosis forms were found on 7 cases $(3.6 \%)$, mainly in cattle of over 4 years old. Organ partial seizures involved 184 carcasses $(94.8 \%)$ while 10 whole carcasses were seized $(5.2 \%)$ depending on the progressive forms of tuberculosis, the general body condition of the animal and affected organs. The main organs seized were the head and lungs, with respectively rates of $63.4 \%$ and $44.8 \%$ cases (Table 7 ).

Table 7: Distribution of organs partial seizures.

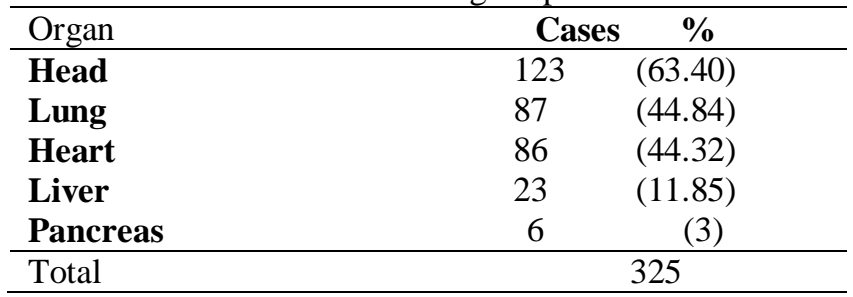

According to the slaughterhouse data recorded, in 753 days of slaughter during the period from September $1^{\text {st }} 2013$ to October $31^{\text {st }} 2015$, 26,060 cattle were slaughtered, of which 514 showed lesions of tuberculosis like lesions. The overall daily prevalence was estimated to $1.97 \%$ and the daily 
average to $2.1 \%$ with a $95 \%$ confidence interval of 1.85 to 2.4 .During the study period from June $20^{\text {th }}, 2014$ to July $13^{\text {th }} 2015$; while working under sufficient light and giving enough time to inspect each carcass; out of 4,198 cattle examined according to the regulatory protocol, 194 carcasses showed suspicious lesions of tuberculosis giving an estimated overall daily prevalence of 4,6\% and the daily average at 5,4\%(95\% CI: 4.7-6.1\%) (Table 8). This value, compared to that obtained from the slaughterhouses registered data is more than twice the estimated average $(R R=2.34)$. This assumes that routine inspection leaves more than $50 \%$ of animals with suspicious lesions.

Table 8: Observed and estimated daily average prevalences

\begin{tabular}{|c|c|c|c|c|c|c|c|c|}
\hline & $\begin{array}{l}\text { Study } \\
\text { period }\end{array}$ & $\begin{array}{l}\text { Slaughtered } \\
\text { cattle } \\
\text { number }\end{array}$ & $\begin{array}{l}\text { Cattle } \\
\text { with } \\
\text { like } \\
\text { lesions } \\
\text { number }\end{array}$ & $\begin{array}{l}\text { Global } \\
\text { prevalence } \\
(\%)\end{array}$ & $\begin{array}{l}\text { Daily } \\
\text { average } \\
\text { prevalence }\end{array}$ & $\begin{array}{l}\text { confidence } \\
\text { interval IC } \\
(95 \%)\end{array}$ & $\begin{array}{l}\text { Min } \\
- \\
\text { Max }\end{array}$ & $\begin{array}{l}\mathrm{RR} \\
\text { (relative } \\
\text { risk) }\end{array}$ \\
\hline $\begin{array}{l}\text { Slaughterhouse } \\
\text { records }\end{array}$ & $\begin{array}{c}753 \text { day }^{*} \\
(09 / 09 / 13 \\
- \\
10 / 31 / 15)\end{array}$ & 26060 & 514 & 1,97 & 2,1 & 1,8 to 2,4 & $\begin{array}{l}0- \\
50\end{array}$ & \\
\hline $\begin{array}{c}\text { Slaughterhouse } \\
\text { study }\end{array}$ & $\begin{array}{c}110 \text { day }^{*} \\
(05 / 26 / 14 \\
- \\
07 / 13 / 15)\end{array}$ & 4198 & 194 & 4,6 & 5,4 & 4,7 to 6,1 & $\begin{array}{c}1,1- \\
25\end{array}$ & $\begin{array}{c}2,34 \\
(1,99- \\
2,75)\end{array}$ \\
\hline
\end{tabular}

\section{B-Results of Mycobacterium cultures}

Globally among 390 samples, 279 (71.5\%) showed a positive mycobacteria culture. Depending on the medium used, the relative frequency of positive isolates per culture is shown in the Figure 1. The latter shows that the LJP medium offers the best isolation result of mycobacteria with a success rate of $80.5 \%$, followed by the Herrold medium $78.3 \%$.

In our study, out of 194 cattle with tuberculous like lesions, 166 showed a positive result in the Mycobacterium isolation, which means an isolation frequency of $85.6 \%$. 


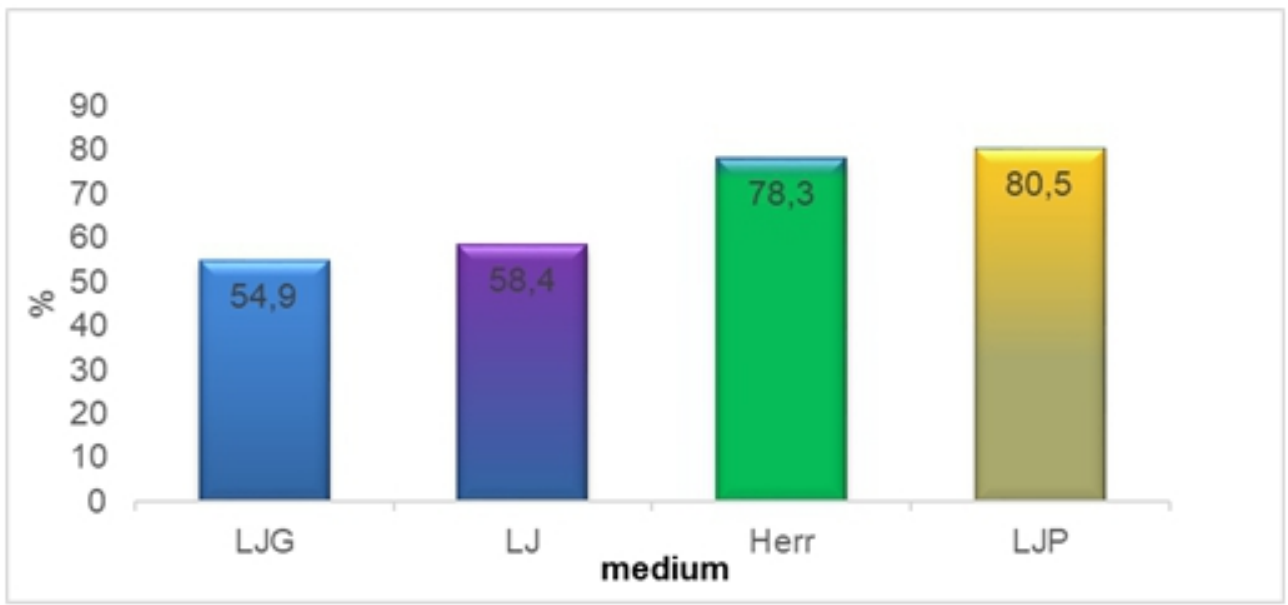

Figure 1: Mycobacterium isolation frequency according to the culture medium Lowenstein-Jensen without glycerine (LJ); Lowenstein-Jensen with glycerine (LJG); Herrold; Lowenstein-Jensen enrichied with pyruvate (LJP).

\section{Discussion}

The majority of tuberculous cattle are from dairy-type breeds. This shows the lack of specialization of farms where a dairy genetic potential can be sacrificed in slaughterhouses. Dairy farming has long been one of the priority axes of agricultural policies in Morocco.According to Benlekhal et al. (2012), improved breeds (pure and crossed) constitute $82 \%$ of cattle breeds in irrigated areas .It's the case of the study area.

In this study, BTB gross lesions were found most frequently in the lungs and lymph nodes of thoracic cavity, followed by lymph nodes of the head. These findings indicate that inhalation might be the principal route of BTB infection in cattle. Whipple et al. (1996) has reported that $60 \%$ of tuberculous lesions were localized in thoracic lymph nodes versus $26.7 \%$ in head ones. The same findings were observed in Australia (Tammemagi et al.,1973).In Mexico, according to Miliano-Suazo et al. (2000), $49.2 \%$ of lesions involved the retropharyngeal lymph nodes. In Algeria, Sahraoui et al.(2008) mentioned that the distribution of injuries showed a violation of respiratory lymph nodes with a rate of 76.92\%.Furthermore, Corner (1994) had reported that up to $95 \%$ of cattle with BTB gross lesions could be identified by examination of the lung and associated lymph nodes in agreement with other studies (Whipple et al., 1996; Pritchard, 1988 ; Teklu et al., 2004).

The predominance of the stabilized primary complex could be explained by the young age of the animals slaughtered, as $79 \%$ of cases with this form are less than 4 years old.

Of the 194 carcasses inspected, forms of generalized tuberculosis were noted in $7(3.6 \%)$ of them mainly in cattle over 4 years of age. According to 
Nassar et al.(1994) in Brazil, Demelash et al., (2009) in Ethiopia, Aljameel et al.( 2014) in Sudan and Youssef and Ahmed, (2014)in Egypt, the generalized form represents between 2.5 and $20.5 \%$ of cases of seizure at slaughterhouse level.

The overall daily prevalence of $4.6 \%$ found in the current study is higher compared to the findings of previous studies performed with similar diagnosis methods in Moroccan slaughterhouses. According to the national office of food safety (ONSSA), bovine tuberculosis is rife in Morocco in the enzootic state in cattle farms. Indeed, this disease is regularly observed in national slaughterhouses (with an average prevalence of $1.7 \%$ recorded during the period 2000-2010) during veterinary inspections carried out by ONSSA veterinary inspectors (ONSSA, 2017). It is also greater than that of $1.97 \%$ calculated from local slaughterhouse database between September 2013 and October 2015. In fact, during our study period an attempt was made to take the time necessary to inspect all suspect carcasses under an appropriate lighting and by applying rigorously the inspection protocol. This shows that in a context known for the dilapidated state of infrastructure at the slaughterhouse level, where adequate lighting during night inspection, especially at the level of rural abattoirs, can sometimes be lacking, cases with insidious tuberculosis can escape to the veterinary inspection. In Ethiopia, Demelash et al. (2009), Mihreteab and Indris (2011) reported respectively 10,2 $\%$ and $2,7 \%$ as abattoir prevalence. In Mexico as well, meat inspection at slaughterhouses demonstrated a frequency of $16 \%$ of BTB lesions (MilianoSuazo et al., 2000).In Algeria, Sahraoui et al. (2008) estimated the overall prevalence to $3.58 \%$.

According to Demelash et al. (2010); Dechassa (2014); Mihreteab and Indris (2011), many factors may influence the effectiveness of the inspection at slaughterhouse ; such as the inspection method, the stage of the lesions, the lack of training of the inspection staff, the lack of a regular system for assessing the competence of meat inspectors, the workload (number of carcasses per inspector and inspection time per carcase), the failure of the slaughter infrastructure; for example, insufficient lighting during night inspections, the possible direct or indirect influence of butchers on the inspectors' decision, especially when the seized parts show little or no visible lesions. Such problems are often reported in developing countries where the access of butchers and workers is tolerated during meat inspection. In Morocco, there are 200 municipal and nearly 800 rural slaughterhouses. The province of $\mathrm{El}$ Jadida is home to fifteen rural and three municipal slaughterhouses including El Jadida, which produces more than $30 \%$ of the province's controlled meat. It is the only one to have an air handling system, while the others are in fact traditional, with a ground slaughter and preparation of the carcass on the spot. At the beginning of 2018, the veterinary services 
opted for the delegation of veterinary inspection missions to the mandated sanitary veterinarians (private practitioners) to fill the lack of veterinary officiel inspectors and support the health control in the rural abattoirs. In most abattoirs in Doukkala region, animals are slaughtered during the night to provide consumers with fresh raw meat the next morning. In most rural slaughterhouses where the electric power supply doesn't exist or is insufficient, proper detection of BTB gross lesions may be difficult, consequently, more infected carcasses could escape to control.

However, the prevalence of BTB-like lesions showed in this study is relatively lower as compared to the prevalence of the disease in dairy farms in Morocco. Indeed, the national survey, conducted in 2004, showed an individual cattle prevalence of $18 \%$ and a herd prevalence of $33 \%$ (FAO, 2011). This is also in line with other studies conducted in other countries indicating lower infection rates in beef than in the dairy cattle (Pritchard, 1988). The culture detected Mycobacterium in two cachectic cows that did not show post-mortem lesions. Results of various studies have indicated that in some cattle infected with $M$. bovis gross lesions are not visible in the tissues examined at slaughter (Whipple et al., 1996 ; Teklu et al., 2004). Actually, the sensitivity of gross post-mortem examination is affected by the method employed and the anatomical sites examined (Corner, 1994).

The frequency of the samples used in this study depends on the progressive stage of BTB lesions observed during the inspection. The dominance of pulmonary and retropharyngeal lymph nodes and pulmonary and hepatic parenchyma reflects the high frequency of the primary complex thus the inhalation is the dominant route of infection.

Laboratory investigations applied to macroscopic lesions taken from 194 tuberculous cattle resulted in an overall 85.6\% Mycobacterium isolation frequency. LJP and Herrold media with a success rate of $80.5 \%$ and $78.3 \%$, respectively, obtained the best isolation results for mycobacteria. This is in agreement with the previously reported studies that reported both media promote the growth of $M$. bovis and that M. bovis is by far the most isolated on tuberculous lesions of cattle (Corner and Nicolacopoulos, 1988; WHO, 1994; Corner et al.,2012).It would therefore be practical to associate the two media for the following reasons: their ability to allow the growth of other species of mycobacteria, including M. tuberculosis and M.avium complex; their great sensitivity and characteristic aspect of the colonies; their cost price remains affordable; LJP enhances growth of $M$. bovis and $M$. africanum (increase in size and number of colonies) and the Herrold medium promotes the growth of the MAP by adding growth factors (Mycobactin). 


\section{Conclusion}

The findings of the study showed that the slaughterhouse prevalence of bovine tuberculosis in the studied area seems higher. The comparison between the estimated overall daily prevalence and that obtained from the slaughter database assumes that routine inspection leaves more than $50 \%$ of animals with suspicious lesions. A large-scale surveillance program is needed to estimate the apparent and true prevalence of bovine tuberculosis. The laboratory isolation frequency of mycobacteria from TB lesions was $85.6 \%$. The combination of LJP and Herrold media increases the chances of isolation of mycobacteria.

\section{Acknowledgements}

The authors are grateful to the Staff of Doukkala slaughterhouses for their good willing and valuable cooperation during the different stages of this study.

\section{References:}

1. Aljameel, M. A, Abdel Wahab, M.B, Fayza, A.O, El Tigani, A.E, \& Abdellatif, M.M. (2014). Occurrence of bovine tuberculosis at Nyala abattoirs in South Darfur State, Sudan. Revue d'élevage et de médecine vétérinaire des pays tropicaux. 67 (2) : 61-65.

2. Ameni, G., Erkihun, A. (2007). Tuberculosis on small-scale dairy farms in Adama Town, central Ethiopia, and farmer awareness of the disease. Revue Scientifique et Technique (International Office of Epizootics) 26 (3) : 711-719.

3. Benlekhal, A., Tazi, S., Naimi, N., \& Rifi, O. (2012). Analyse rétrospective de programmes d'amélioration génétique de bovins et perspectives d'évaluation dans le cadre du plan Maroc Vert. Présentation orale au séminaire de l'Association Nationale pour la Production Animale (ANPA), Rabat (7 juin 2012). http:/agrimaroc.net/ANPA/ANPA_2012/ benlekhal_anpa2012/Benlekhal_2012.pdf. (consulté le 02/06/2016)

4. Biet, F., Boschiroli, M.L., Thorel, M.F. \& Guilloteau, L. A. (2005). Zoonotic aspects of Mycobacterium bovis and Mycobacterium avium -intracellulare complex (MAC). Veterinary Research. 36 : 411-436.

5. Bulletin Officiel Maroc (2001). Arrêté du Ministre de l'Agriculture du Développement Rural et des Eaux et Forêts n¹40901 du 26 juillet 2001, page 984.

6. Corner, L.A. (1994). Post mortem diagnosis of M. bovis infection in cattle. Veterinary Microbiology. 40 : 53-63.

7. Corner, L.A., \& Nicolacopoulos, C. (1988). Comparison of media used for the primary isolation of Mycobacterium bovis by veterinary and 
medical diagnostic laboratories. AustralianVeterinary Journal. 65 : 202-205.

8. Corner, L.A., Gormley, E., \& Pfeiffer, D.U. (2012). Primary isolation of Mycobacterium bovis from bovine tissues: conditions for maximising the number of positive cultures. Veterinary Microbiology. 156: $162-171$.

9. Cosivi, O.,Grange, J.M., Daborn, C.J., Raviglione, M.C., Fujikura, T., Cousins, D.,Robinson, R.A., Huchzermeyer, H.F. \& Meslin, F.X. (1998). Zoonotic tuberculosis due to Mycobacterium bovis in developing countries. Emerging infectious diseases. 4 : 59-70.

10. Cousins, D., Manning, EJ.B., \& Collins, M.T. (2001). (eds.). Revue Scientifique et Technique (International Office of Epizootics). 20 : 7185.

11. Dechassa, T. (2014). Gross pathological lesions of bovine tuberculosis and efficiency of meat inspection procedure to detectinfected cattle in Adama municipal abattoir. Journal of veterinary Medicine and Animal Haelth. 6 (2) : 48-53.

12. Demelash, B., Inangolet, F., Oloya, J., Asseged, B., Badaso, M., Yilkal, A., \& Skjerve, E. (2009). Prevalence of bovine tuberculosis in Ethiopian slaughter cattle based on post-mortem examination. Tropical Animal Health and Production. 41 : 755-65.

13. Demelash, B., Asseged, B., \& Eystein, S. (2010). Diagnostic efficiency of abattoir meat inspection service in Ethiopia to detect carcasses infected with Mycobacterium bovis: Implications for public health. BMC Public Health. 10 : 462.

14. Demelash, B., Inangolet, F., Oloya, J., Asseged, B., Badaso, M., Yilkal, A., \& Skjerve, E. (2009). Prevalence of bovine tuberculosis in Ethiopian slaughter cattle based on post-mortem examination. Tropical Animal Health and Production. 41 : 755-65.

15. FAO. (2011). Principales réalisations depuis l'ouverture de la Représentation de la FAO à Rabat en 1982.Report No. p. 36 .http://www.fao.org/3/a-ba0008f.pdf.(consulté le 13 mai 2016)

16. Fikri A. (1997). Situation de la tuberculose bovine au Maroc. In: Proceedings of the Second International Conference on Animal tuberculosis in Africa and the Middle-East, pp. 11-18, Rabat, Morocco, October 4-6, 1995. Edited by. J. Berrada. M. Bouslikhane and N. Bouchriti. Actes Editions. Morocco

17. Mihreteab, B., \& Indris, B. (2011). Evaluation of Routine Meat Inspection Procedure to Detect Bovine Tuberculosis Suggestive Lesions in Jimma Municipal Abattoir, South West Ethiopia. Global Veterinaria. $6: 172-179$. 
18. Miliano-Suazo, F., Salmar, M.D., Ramirez, C., Payeur, J.B., Rhyan, J.C. \& Santillan, M. (2000). Identification of TB in cattle slaughtered in Mexico. American Journal of Veterinary Research. 61: 86-89.

19. Morris, R.S., Pfeiffer, D.U., Jackson, R. (1994). The epidemiology of Mycobacterium bovis infections. Veterinary Microbiology. 40: 153177.

20. Nassar, A.F., Miyashiro, S., Oliveira, C.G., Pacheco, W.A., \& Ogata, R.A.(1994).Isolation and Identification of Bovine Tuberculosis in a Brazilian Herd (São Paulo). Memóriasdo Instituto Oswaldo Cruz. 102 : 639-642.

21. Neill, S.D., Pollock, J.M., Bryson, D.B., \& Hanna, J. (1994). Pathogenesis of mycobacterium bovis infection in cattle. Veterinary Microbiology. $40: 41-52$.

22. O'reilly, L.M., \& Daborn, C.J. (1995). The epidemiology of mycobacterium bovis infections in animals and man, a review. Tubercule and Lung disease. 76, supplement 1 : 1-46.

23. Office National de la Securité Sanitaire des produits Alimentaires ONSSA. (2017). Tuberculose bovine:Situation sanitaire au niveau national.http://www.onssa.gov.ma/fr/sante-animale/programme-de prophylaxie/tuberculose-bovine .

24. Pritchard, D.G. (1988). A century of bovine tuberculosis, 1888-1988: conquest and controversy. Journal of Comparative Pathology journal. 99 : 357-387.

25. Proskauer, B. and Beck, M. (1898). Infections krankh., Z. Hyg.,18, p128 .

26. Sahraoui,N.,Muller,B., Yalla,D.,Ouzrout,R.,Zinsstag,J.et al.(2008).Ivestigation about the bovine tuberculosis I two Algerian slaughterhouses.African Journal ofAgricultural Research.3:775-778

27. Tammemagi, L., Simmons, G.C., Kelman, R. \& Hall, W.T.K. (1973). A study of tuberculosis-like lesions in cattle slaughtered in Queensland meatworks. Australian Veterinary Journal. 49 : 507-511

28. Teklu, A., Aseged, B., Yimer, E., Gebeyehu, M. and Woldesenbet, Z. (2004). Tuberculous lesions not detected by routine abattoir inspection: the experience of the Hossama municipal abattoir, southern Ethiopia. Revue Scientifique et Technique (International Office of Epizootics). 23 : 957-964

29. United State Department of Agriculture (1985). National Veterinary Services Laboratories Animal and Plant Health Inspection Service Ames IA. Laboratory methods in veterinary mycobacteriology. pp. 554. 
30. Whipple, D.L., Bolin, C.A., \& Miller, J.M. (1996). Distribution of lesions in cattle infected with M. bovis. Journal of Veterinary Diagnostic Investigation. 8: 351-354.

31. World Health Organisation (1994). Report of WHO working group on zoonotic tuberculosis (Mycobacterium bovis), with the participation of FAO, 1994 June 14. Mainz, Germany. Geneva: the Organization, Unpub. Document WHO/CDS/VPH/94.137.

32. Youssef, A.I. \& Ahmed, A.M. (2014). Bovine tuberculosis survey based on meat inspection and microscopic examination in central city abattoir in Ismailia, Egypt and its hazards to the abattoir workers. International Food Research Journal. 21 : 577-582. 